\title{
A decay effect of the growth rate associated with genome reduction in Escherichia coli
}

\author{
Kouhei Tsuchiya', Yang-Yang Cao², Masaomi Kurokawa', Kazuha Ashino', Tetsuya Yomo² and Bei-Wen Ying ${ }^{1 *}$ (D)
}

\begin{abstract}
Background: Bacterial growth is an important topic in microbiology and of crucial importance to better understand living cells. Bacterial growth dynamics are quantitatively examined using various methods to determine the physical, chemical or biological features of growing populations. Due to methodological differences, the exponential growth rate, which is a parameter that is representative of growth dynamics, should be differentiated. Ignoring such differentiation in the growth analysis might overlook somehow slight but significant changes in cellular features of the growing population. Both experimental and theoretical investigations are required to address these issues.

Results: This study experimentally verified the differentiation in growth rates attributed to different methodologies, and demonstrated that the most popular method, optical turbidity, led to the determination of a lower growth rate in comparison to the methods based on colony formation and cellular adenosine triphosphate, due to a decay effect of reading $\mathrm{OD}_{600}$ during a population increase. Accordingly, the logistic model, which is commonly applied to the highthroughput growth data reading the $\mathrm{OD}_{600}$, was revised by introducing a new parameter: the decay rate, to compensate for the lowered estimation in growth rates. An improved goodness of fit in comparison to the original model was acquired due to this revision. Applying the modified logistic model to hundreds of growth data acquired from an assortment of Escherichia coli strains carrying the reduced genomes led to an intriguing finding of a correlation between the decay rate and the genome size. The decay effect seemed to be partially attributed to the decrease in cell size accompanied by a population increase and was medium dependent.

Conclusions: The present study provides not only an improved theoretical tool for the high-throughput studies on bacterial growth dynamics linking with optical turbidity to biological meaning, but also a novel insight of the genome reduction correlated decay effect, which potentially reflects the changing cellular features during population increase. It is valuable for understanding the genome evolution and the fitness increase in microbial life.
\end{abstract}

\section{Background}

Bacterial growth dynamics have been intensively studied at both the experimental and theoretical levels [1-4] due to their broad applications in the food and medical industries and because of the simplicity of the fundamental investigation of determining living systems [5-7]. It is well-known that bacterial growth commonly follows an S-shaped curve on a two-dimensional plane over time the bacterial population. To describe and/or predict $\mathrm{S}$-shaped growth curves, a number of bacterial growth models were proposed, revised and expanded repeatedly to better understand the biological process of bacterial

\footnotetext{
* Correspondence: ying.beiwen.gf@u.tsukuba.ac.jp

${ }^{1}$ School of Life and Environmental Sciences, University of Tsukuba, 1-1-1

Tennodai, Ibaraki 305-8572, Japan

Full list of author information is available at the end of the article
}

growth under varied conditions and/or forms [8-13]. Although the growth curve of the most representative bacterium, Escherichia coli (E. coli), has been examined since the 1930s [14], the indescribable complexity of the growth dynamics of $E$. coli remain and are still under investigation with other models to understand the differential growth dynamics $[15,16]$. Despite the variation in either experimental techniques or theoretical models, the growth rate during the exponentially growing phase is the most important parameter and has a high biological impact; this rate represents the genetic and environmental influences on the bacterial growth dynamics [17-19]. Thus, precise evaluation on the growth rate is highly required for better understanding of growing cells and populations.

(C) The Author(s). 2018 Open Access This article is distributed under the terms of the Creative Commons Attribution 4.0 International License (http://creativecommons.org/licenses/by/4.0/), which permits unrestricted use, distribution, and 
Experimentally, bacterial growth rate is quantified by varied techniques and is dependent on different principles of chemistry, physics and biology [20,21], such as assays of optical turbidity, colony formation, cellular adenosine triphosphate (ATP) and particle counts [22-25]. The most commonly used method is the conventional method to measure the optical turbidity of a bacterial culture (optical density at a wavelength of $600 \mathrm{~nm}$, $\left.\mathrm{OD}_{600}\right)$ due to its easy manipulation. To date, this method seems to be the most frequently used tool for assessing high-throughput assays of bacterial growth in microplates and colonies $[4,6,26,27]$, and for computational and systematic analyses of bacterial growth dynamics $[26,28,29]$. These up-to-date studies are largely based on fitting the logistic model $[30,31]$ to experimental data acquired from temporal reads of optical turbidity $\left(\mathrm{OD}_{600}\right)$. Since the measurement of $\mathrm{OD}_{600}$ detects light transmitted through a cell culture by a spectrophotometer, the changes in absorbance may not always accurately correlate to the changes in the number of living cells. Although the optical turbidity was confirmed to be reliable for estimation of bacterial growth rate, the calibration of the optical measurements was required [32]. Taking account of these issues, the growth data reading $\mathrm{OD}_{600}$ might neglect potential changes in the cellular features occurred during population increase.

To estimate how much difference in growth rates could be caused by the difference in methods, the growth rates of various $E$. coli strains were evaluated by varied methods in parallel. Furthermore, to see whether the improved evaluation of growth dynamics would identify any overlooked cellular features of the growing population, a large data set composed of hundreds of growth curves of an assortment of $E$. coli cells carrying reduced genomes were analyzed. As a consequence, the commonly used growth model of the logistic equation was revised by introducing a new parameter of biological importance, and a correlation between genome reduction and the logistic parameters was observed for the first time, owing to the modified logistic model. In a word, this study offers an improved growth model based on optical turbidity and a novel finding of the correlation between genome reduction and the growth related parameters, which are linked to the changes in the cellular features.

\section{Results}

Lower growth rates evaluated by the optical turbidity

The wild-type E. coli strain W3110 was cultured in minimal medium M63 and was temporally sampled in three different assays to measure the optical turbidity $\left(\mathrm{OD}_{600}\right)$, colony formation (colony forming unit, CFU) and ATP abundance, which are based on the physical, biological and chemical properties of the growing cell population, respectively. Although these three methods are well established and widely used in experimental and theoretical studies on bacterial growth, it is unclear whether they result in a common conclusion regarding bacterial growth. The three methods of measuring the $\mathrm{OD}_{600}$, CFU and ATP represent the density of the biomass, number of living cells and cellular activity, respectively. The growth dynamics represented by the changes in these different parameters must be varied in consequence. To verify this assumption, we performed three assays in parallel on identical cell cultures. According to the growth curves generated from the $\mathrm{OD}_{600}$, CFU and ATP, the growth rates were calculated by regression toward the time sampling records during the exponential growth phase and as described in the Materials and Methods. Repeated cell cultures $(N=3 \sim 5)$ showed significant differentiation of the growth rates estimated by measuring the optical turbidity (OD), colony formation (CFU) and ATP abundance (Fig. 1). The growth rates estimated by measuring the CFU and ATP were comparable, whereas those from $\mathrm{OD}_{600}$ were lower $(p<0.05)$, regardless of identical population growth. The results demonstrated that the bacterial growth dynamics, which are represented by changes in optical turbidity, were different from those evaluated by changes in the number of active cells, consistent to the previous report [32]. How and what caused the differences in growth rates and whether the differences were common under other conditions were further investigated by comparing two representative methods, $\mathrm{OD}_{600}$ and $\mathrm{CFU}$.

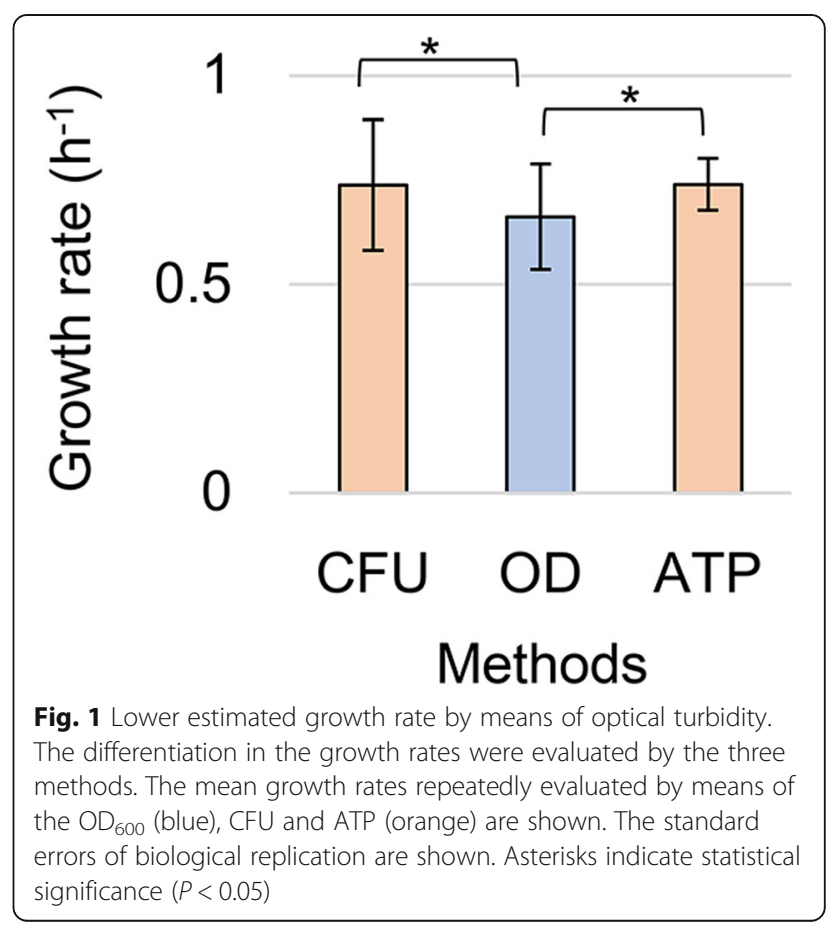




\section{Decay effect in optical turbidity triggered the lower estimated growth rate}

A decay effect was observed when the optical turbidity results were compared to the records of colony counts and $\mathrm{OD}_{600}$ values. Both the $\mathrm{CFU}$ assay (Fig. 2a, upper) and $\mathrm{OD}_{600}$ reads (Fig. 2a, middle) were performed in parallel to monitor the same population growth. The temporal changes in both records were supposed to be similar. Nevertheless, a temporal decrease in the ratio of the $\mathrm{OD}_{600}$ reads and CFU counts was observed (Fig. 2a, bottom). Since the decrease was initiated from the early exponential phase, the growth rates evaluated by optical turbidity $\left(\mu_{\mathrm{OD}}\right)$ were lower than those evaluated by colony formation $\left(\mu_{\mathrm{CFU}}\right)$ (Fig. 1b); this decrease was considered to be due to the decay effect of the $\mathrm{OD}_{600}$ values. It was carefully tested whether the decay effect was caused by limitations of the optical measurement. No significant differentiation in the optical reads were detected during the exponential growth phase $\left(\mathrm{OD}_{600}<0.5\right)$ compared with the significant decrease in the reads of $\mathrm{OD}_{600}$ during the stationary phase $\left(\mathrm{OD}_{600}>1\right)$ (Additional file 1 : Figure S1). It was verified that the decay of the $\mathrm{OD}_{600} /$ CFU ratio during the exponential phase was not attributed to mechanical errors of the optical reads but was mainly due to biological issues, such as a difference in cellular properties.

The lower estimated growth rate according to optical turbidity was also detected either under other growth conditions or in other genotypes. Wild-type $E$. coli cells W3110 grown under various conditions (D3, D4 and $\mathrm{Cm}$ described in the figure legend) also showed lower growth rates $(N=3, P<0.05)$ estimated by $\mathrm{OD}_{600}$ (Fig. 2b). In addition, the growth dynamics of four different $E$. coli strains with reduced genomes (Strain Nos. 7, 14, 20 and 28), which were previously constructed [33] and characterized [34], were assayed by the two methods $(\mathrm{N}=3 \sim 4)$. Similarly, the values of $\mu_{\mathrm{OD}}$ tended to be smaller than those of $\mu_{\mathrm{CFU}}(P<0.05)$ regardless of the multiple deletions of genomic sequences (Fig. 2c). The results indicated that the lower growth rates estimated
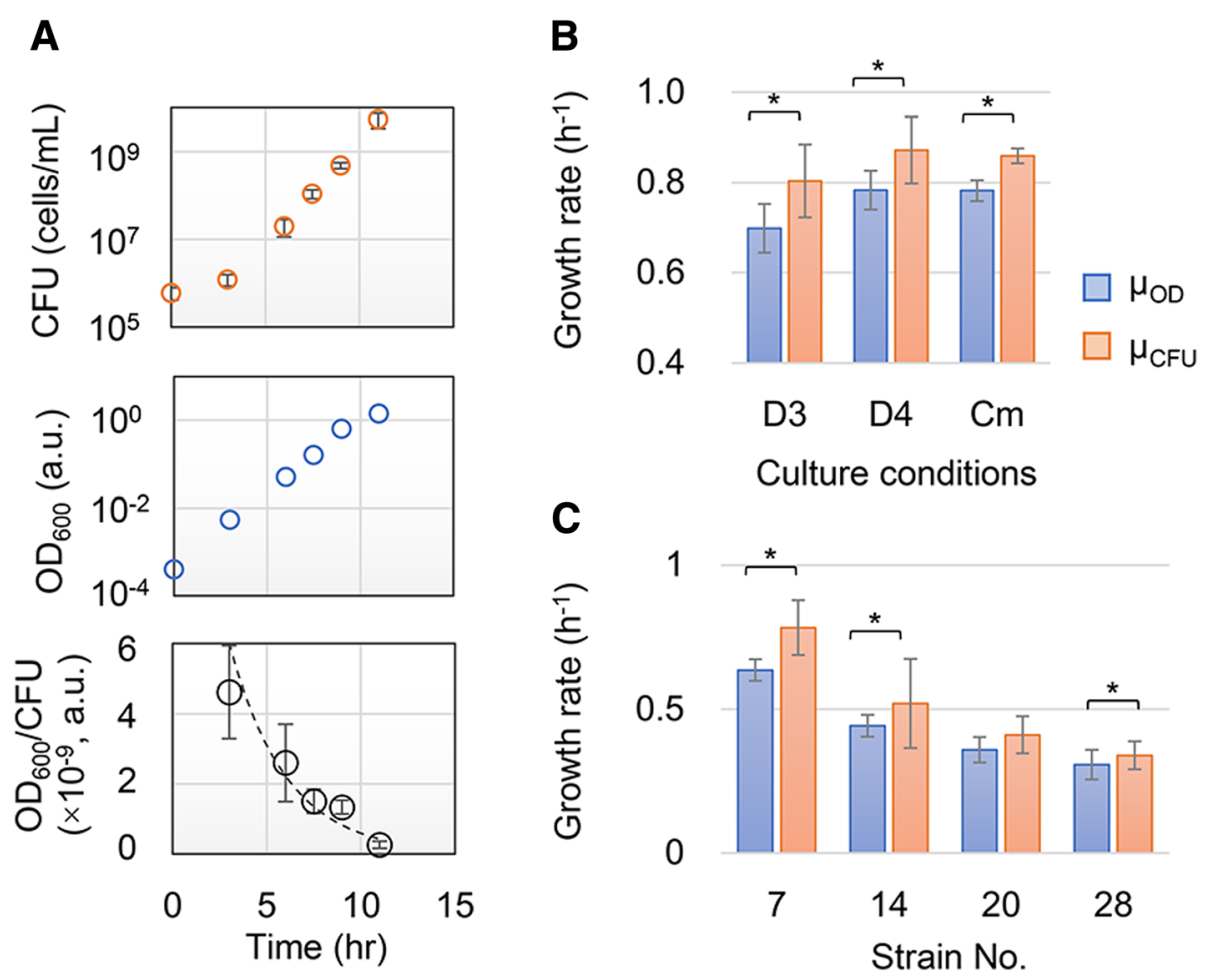

\section{Culture conditions}

Fig. 2 Differentiated growth rates estimated by means of the optical turbidity and colony formation. a. Repressed increase of $\mathrm{OD}_{600}$ in comparison to that of CFU. The temporal changes in CFU (upper), $\mathrm{OD}_{600}$ (middle), and the ratio of the two reads (bottom) of identical population growth are shown. Error bars indicate the standard errors of the assays. $\mathbf{b}$. The growth rates under varied growth conditions. Growth of the same wild-type $E$. coli cells growing under the different conditions (D3, D4 and Cm) was analyzed in parallel by the two methods. D3 indicates that the cell growth that started from the pre-culture reached the stationary phase with a 1000-fold dilution in fresh medium. D4 indicates that the cell growth that started from the pre-culture remained in the exponential phase with a 10,000-fold dilution in fresh medium. $\mathrm{Cm}$ refers to cell growth in the presence of a low concentration of antibiotics ( $15 \mu \mathrm{g} / \mathrm{mL}$ chloramphenicol). The growth rates evaluated by $\mathrm{OD}_{600}$ and CFU are indicated as $\mu_{\mathrm{OD}}$ and $\mu_{\mathrm{CFU}}$, respectively. $\mathbf{c}$. The growth rates of the various genotypes. The growth dynamics of $E$. coli cells of four reduced genomes were analyzed by the two methods in parallel. Strain Nos. 7, 14, 20 and 28 indicate multiple deletions of approximately 251, 710, 899 and 982 kbs from the wild-type genome W31 10, respectively. The standard errors of the biological replication are indicated, and asterisks indicate the statistical significance $(P<0.05)$ 
by optical turbidity, which is the most commonly used method in bacterial growth studies, frequently occurred in different genotypes and under various growth conditions. Collectively, a lower $\mu_{\mathrm{OD}}$ than $\mu_{\mathrm{CFU}}$ was found to be common, which indicated the growth associated cellular changes might occur.

\section{A decay rate introduced into the logistic model offset the decay effect}

Considering the cellular changes that accompanied growth, a modified logistic model is proposed in the present study by introducing a novel parameter, the decay rate. The theoretical revision differed from the previous study that applying a numeral calibration of the measurements [32]. The logistic equation is the most popular model that is used to represent bacterial growth dynamics. This equation is commonly applied to fit growth curves based on optical turbidity, especially in systems and computational biology to understand the dynamics of living systems. Considering the decay effect in $\mathrm{OD}_{600}$ during population growth, the logistic model was revised. A new parameter, the decay rate $(d)$, was defined, which has the same unit of $h^{-1}$ as the growth rate.

Logistic model:

$$
N(t)=\frac{K}{1+\frac{K-N 0}{N 0} \times e^{-r t}}
$$

Modified logistic model:

$$
N(t)=\frac{K}{1+\frac{K-N 0}{N 0} \times e^{-r(1-d t) t}}
$$

where $N_{O}, K, r$, and $d$ represent the initial cell concentration, saturated cell concentration, growth rate, and decay rate, respectively.

To evaluate whether the modified logistic model was applicable, a large number of growth data sets were fitted to the two logistic equations. A total of 710 precisely measured growth curves from 29 different $E$. coli strains in either rich (Luria-Bertani broth, LB) or poor (M63) medium were subjected to the theoretical fitting. The histograms of parameter $K$ estimated by the two models were completely overlapped (Fig. 3a). However, the histograms of the growth rate, $r$, were different between the two models (Fig. 3b). The mean growth rates estimated by the modified logistic model were larger and with a larger variation. The results indicated that the addition of the decay rate $d$ in the logistic model did not influence $K$, the saturated population density or the carrying capacity, but contributed to the growth rate $r$ independent of the nutritional conditions for population growth (Additional file 1: Figure S2).

Intriguingly, the modified logistic model presented improved goodness of fit compared to the original model. The residual errors, which were designated as the sum of the squared errors (SSE), of fitting the total 710 growth curves to the modified logistic model were smaller than those from the original model (Fig. 4a). Thus, the goodness of fit $\left(R^{2}\right)$ was better for the modified logistic model (Fig. 4b), independent of either the genotype or medium (Additional file 1: Figure S3). The results showed that the modified logistic model better explained the growth dynamics of bacterial cells, which strongly indicated that the revision of the logistic model was theoretically practical. Considering the fact that the increase in $\mathrm{OD}_{600}$ was decided not only by exponential changes in the number of cells but also by unclear changes in the cellular contents, such as the cell size and macromolecular abundance, revision of the logistic model by introducing an additional parameter of the decay rate was also biologically reasonable.

\section{A correlation between the decay rate and the genome reduction in a nutritional dependent manner}

Interestingly, a correlation between genome reduction and the decay rate was observed when applying the modified logistic model to the experimental bacterial growth data. Fitting the growth data of the reduced genomes to the modified logistic equation, as described
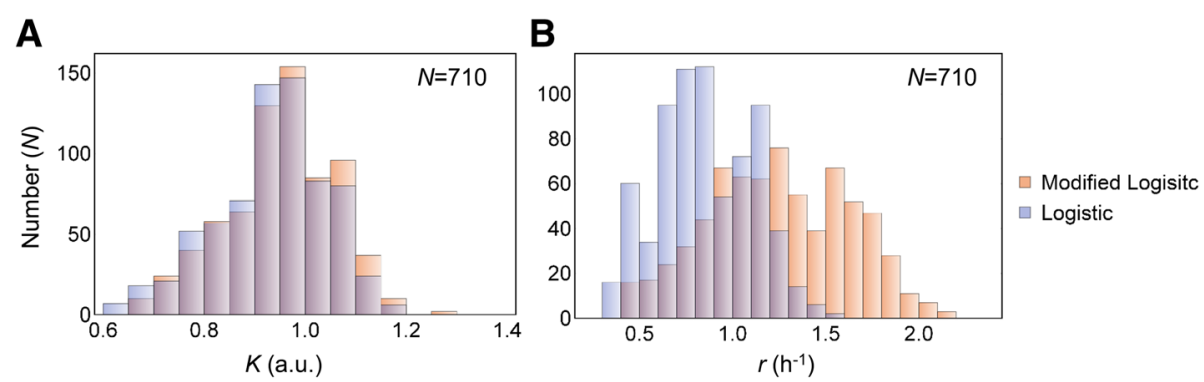

Fig. 3 Growth parameters estimated by the two logistic models. a. Histograms of the saturated density $K$ estimated by the two models. $\mathbf{b}$. Histograms of the growth rate $r$ estimated by the two models. Transparent blue and orange colors represent the theoretical fitting of experimental data with the logistic and modified logistic models, respectively. The number of growth curves is also indicated 

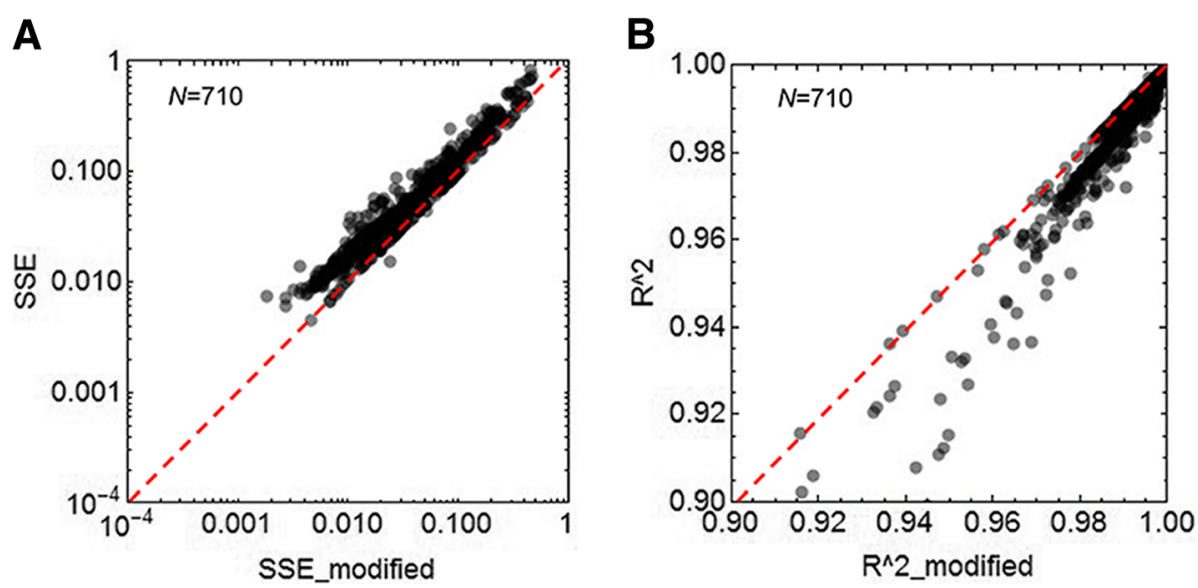

Fig. 4 Improved fitting efficiency of the modified logistic model. a. A comparison of the fitting residual errors between the two models. The fitting errors are represented by the sum of squares error, SSE. b. A comparison of the goodness of fit between the two models. The goodness of fit is represented by the coefficient of determination, $R^{2}$. The broken red lines indicate the equivalent fitting efficiency of the two models. The number of growth curves used is also indicated

above, resulted in the estimated constants of $r$ and $d$, which are the growth and decay rates, respectively. Both the mean growth rates and mean decay rates of the repeated growth assays $(N=12 \sim 28)$ were calculated for a total of 29 strains (Nos. $0 \sim 28$ ). The results showed that a decrease along with a genome reduction was detected not only in the growth rates but also in the decay rates (Fig. 5a). The larger the genome reduction, the lower the detection of decay. This finding was supported by the fact that the changes in growth rates evaluated by $\mathrm{OD}_{600}$ and CFU were smaller with the genome reduction (Fig. 5b). Fewer changes between $\mu_{\mathrm{OD}}$ and $\mu_{\mathrm{CFU}}$ resulted in a smaller decay effect in $\mathrm{OD}_{600}$. Reduction of the genome size might change the cellular properties that are linked to population growth.

A correlation between the growth rate and genome reduction has been previously reported according to the manual calculation [34]. The same conclusion was drawn from the theoretical fitting suggested here, and the modified logistic model was applicable. Notably, an

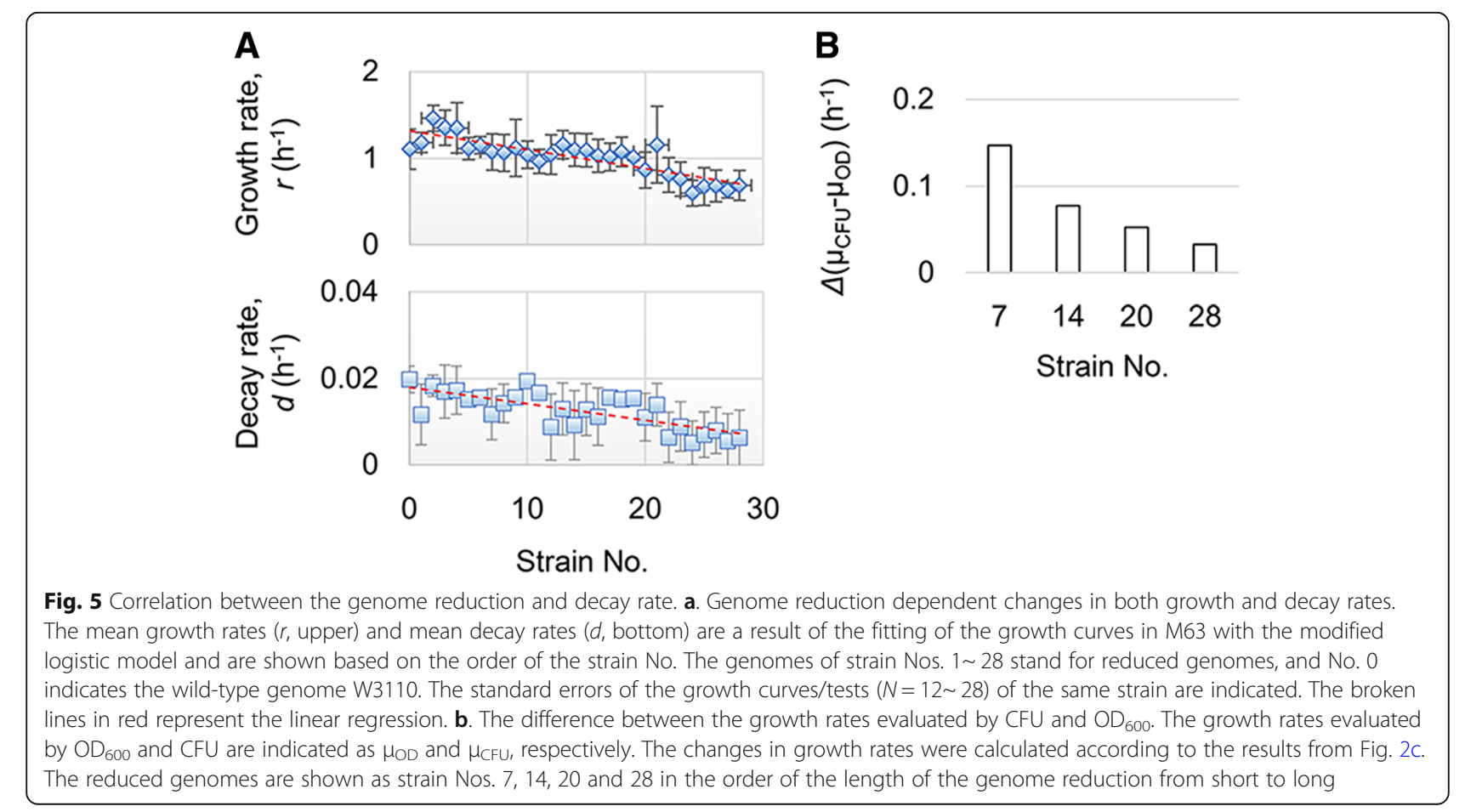


additional conclusion of the correlation between the decay rate and genome reduction was drawn based on the modified logistic model. The Pearson correlation coefficients of the genome size to the decay rate were highly significant (cor $=0.684, p=4 \mathrm{e}-5$ ) and were comparable to the growth rate $(c o r=0.772, p=6 \mathrm{e}-7)$. This result indicated that the changing cellular features that accompanied the population growth disturbed the optical properties. Note that the decline in the decay rates of the reduced genomes was significantly detected in the cell growth in the M63 medium but not LB medium (Additional file 1: Figure S5), which indicated that the nutritional richness affected the significance of the cellular changes that contributed to the decay rate. This finding agreed with the result that the difference of the fitting goodness between the two models was slight in LB but significant in M63 (Additional file 1: Figure S3).

\section{The decay rate was partially attributed to the changes in cell size}

As the decay rate of the reduced genome was much smaller than that of the wild-type genome (Fig. 5), we investigated whether any biological features could be identified to explain the decrease in the decay rate. As the growth rate is often discussed with cell size [35] and the genome reduction was found to somehow contribute to the change in cell size [34], growth accompanying changes in cell size might be linked to the decay rate. To verify the assumption, cells carrying either the wild-type (No. 0) or the reduced (No. 28) genomes were cultured in M63 medium, and the size distributions at a varied population density were analyzed. Since the cell size of an identical population often showed a large variation
(Fig. 6a), the median of the cell size of the population was used as a representative parameter [36]. The results showed that the median cell size was smaller compared to the increase in population density (Fig. 6b, triangle). The feature of a higher population density linked to a smaller cell size was clearly identified in the wild-type genome, but not in the reduced genome (Fig. 6b, circle). This result suggests that the population density dependent size effect became insignificant due to genome reduction, consistent with the findings of the decay rate, and significantly declined in the reduced genome (Fig. 5). Thus, cell size changes of the growing population might be one of the reasons that cause the decay effect in $\mathrm{OD}_{600}$. Population density dependent changes in cell size were supposed to happen during the stationary phase due to nutritional depletion [35, 37]; however, the results showed that the changes in cell size also occurred even in the exponential phase. This result agrees well with the temporal decrease in the ratio of $\mathrm{OD}_{600} / \mathrm{CFU}$ from the exponential phase (Fig. 2a).

\section{Discussion}

Growth assay on an assortment of E. coli strains observed a common feature of lower $\mu_{\mathrm{OD}}$ than $\mu_{\mathrm{CFU}}$. This result was attributed to the repressed increase in the $\mathrm{OD}_{600}$ value during population growth, which suggests that the changes in the cellular features were not always strictly correlated to the changes in cell number or even during the exponential growth phase. This experimental finding raised the question of whether the theoretical models that use the reads of optical turbidity properly describe bacterial growth. Because the temporal assay using $\mathrm{OD}_{600}$ is convenient and because it is easy to perform continuous reads in theoretical studies, a revision
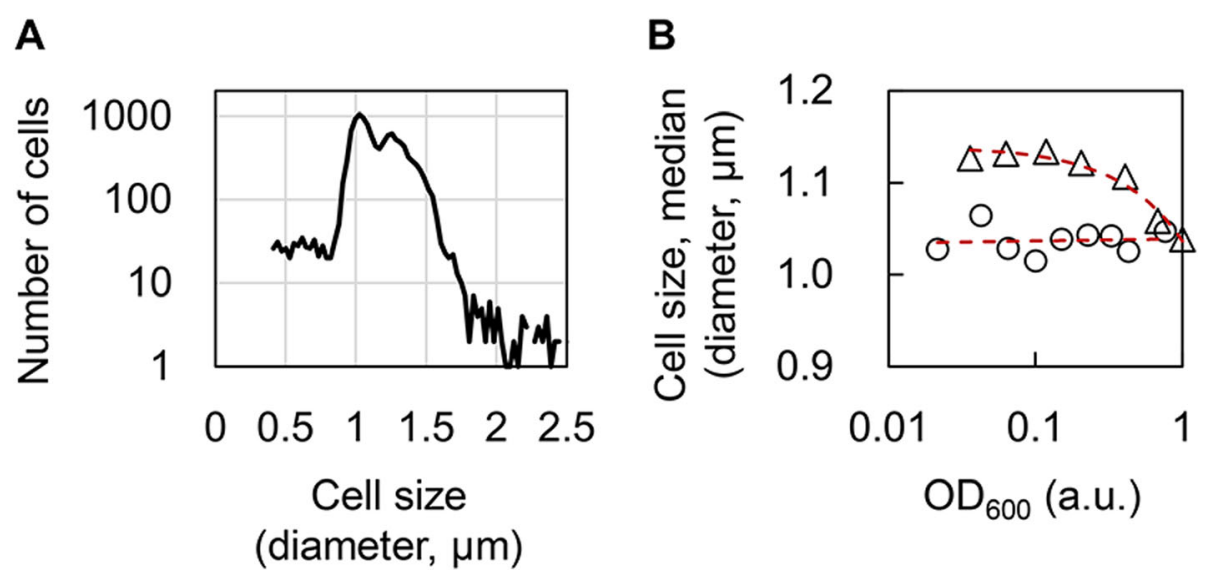

Fig. 6 Relationship between the cell size and population density. a. Size distribution of an identical cell population. A size distribution of more than 10,000 E. coli cells growing exponentially in M63 is shown as an example. $\mathbf{b}$. The relationship between the population density and cell size. E. coli cells of either the wild-type (No. 0, triangle) or the reduced (No. 28, circle) genomes were grown in M63. The cell size of the culture at various population densities was measured, and the median size of the cell population was used for analysis. The red broken lines represent the exponential regression 
of the existing growth model through a consideration of the decay in $\mathrm{OD}_{600}$ was examined for the first time. In comparison to the original model, the revised logistic model proposed in the present study showed a better fitting goodness, indicating that this modified growth model was practical.

In addition, although the parameter of $r$ is known to be a constant value in the logistic model, the growth rate of $\mu_{\mathrm{OD}}$ was somehow inconstant during the exponential phase when monitoring by the microplate reader (Additional file 1: Figure S4), probably due to the decay effect, which was consistent with the finding that the increase of $\mathrm{OD}_{600}$ was slower with population growth in comparison to that of CFU (Fig. 2a). Therefore, the parameter of $r$ in the logistic equation, which presents the exponential changes of a population increase, might represent the growth rate of $\mu_{\mathrm{CFU}}$ and changes in the number of cells without considering changes in cellular features. Because the logistic model was widely applied to growth data based on reads of $\mathrm{OD}_{600}$, the additional decay rate, which compensated for the decrease in $\mu_{\mathrm{OD}}$, met the decay effect and contributed to the effective logistic fitting of bacterial growth based on optical turbidity.

Systematic analyses on the growth dynamics of the $E$. coli cells holding the reduced genomes led to a new finding on the correlation of the decay rate to genome reduction. This finding evidently revealed the biological impact of the revision of the logistic model by incorporating the decay rate $(d)$, which provided a better understanding of the bacterial growth dynamics in depth. Further investigation on the changes in cell size accompanied growth experimentally demonstrated the biological basis of the newly introduced parameter of the decay rate. The optical turbidity might reflect both the cell number and cell size. The decay rate (i.e., decay effect in optical turbidity) could be partially explained by changes in the cell size/volume accompanied by the population increase, and the significance of the cell size-mediated decay effect was genome/ strain dependent. The modified logistic model included an additional parameter considering the cellular features, such as the cell size, to compensate for the original logistic model, which is often applied to population growth with the quantitative unit of the cell number.

\section{Conclusions}

The present study reconfirmed the methodology mediated variation in growth rates and provided the first example of that the precise growth analysis could bring new findings in bacterial growth. In summary, a decay effect in the bacterial growth rate evaluated by optical turbidity was detected according to the differentiation in growth rates caused by variations in methods. To compensate for the decay effect in $\mathrm{OD}_{600}$ reads, the commonly used growth model of the logistic equation was revised by introducing a new parameter, the decay rate, which was found to be dependent on both the genotype and medium and was partially attributed to changes in cell size. These new findings reveal the biological impact of considering the decay effect in the bacterial growth rate evaluated by optical turbidity. The novel finding of the correlation between genome reduction and the decay rates is highly intriguing and requiring further investigation. In addition, whether the decay rate is universal in bacteria is also a highly interesting question required to be addressed for a better understanding of bacterial growth dynamics.

\section{Methods}

\section{Strains and media}

The E. coli strain W3110 and its derivative strains [33, 34] used in the present study were acquired from the National BioResource Project (NBRP) of the National Institute of Genetics (NIG), Japan. E. coli cells were cultured in minimal medium M63, which contains $62 \mathrm{mM}$ dipotassium hydrogenphosphate, $39 \mathrm{mM}$ potassium dihydrogen phosphate, $15 \mathrm{mM}$ ammonium sulfate, $15 \mu \mathrm{M}$ thiamine hydrochloride, $1.8 \mu \mathrm{M}$ Iron (II) sulfate, $0.2 \mathrm{mM}$ magnesium sulfate, and $22 \mathrm{mM}$ glucose. Preparation of the M63 medium was previously described in detail [27]. The colony formation was detected using LB broth agar, Miller (Sigma Aldrich).

\section{Bacterial growth in the test tubes}

A total of $43 \mathrm{~mL}$ of M63 medium was placed in a $50 \mathrm{~mL}$ Falcon (Watson) tube in which $100 \mu \mathrm{L}$ of the E. coli glycerol stock stored at $-80{ }^{\circ} \mathrm{C}$ was added and well mixed using a vortex. A total of $5 \mathrm{~mL}$ of the mixture was dispensed into eight sterilized glass tubes and cultured at $37{ }^{\circ} \mathrm{C}$ and $200 \mathrm{rpm}$ using a bioshaker (Taitec). The culture was temporally sampled from the late lag phase to the early stationary phase to detect the growing population using three different methods that relied on the physical, biological and chemical properties of bacterial cells, i.e., the optical turbidity, colony formation, and ATP abundance. Sampling was conducted by taking $1.2 \mathrm{~mL}$ of the culture from two out of eight glass tubes, and $1 \mathrm{~mL}$ of the sampled culture was placed in a cuvette to measure absorbance at $\mathrm{OD}_{600}$ (Beckman DU730), and the remaining volume was used for the other two assays. Time sampling was performed rotationally among a total of eight glass tubes, which led to a single growth curve based on the $\mathrm{OD}_{600}$ value. This time course of bacterial growth was conducted repeatedly $(N=3 \sim 5)$. The biological replications varied from the initial pre-culture.

\section{Colony forming unit (CFU) assay}

The colony formation (CFU) assay is a method of estimating the number of viable bacteria in a culture 
solution by counting colonies on the assumption that a microorganism colony that appears on agar medium is derived from one cell. According to the value of $\mathrm{OD}_{600}$, multiple dilution rates of the sampled culture, which varied in order, were performed to obtain 10 to $500 \mathrm{col}-$ onies per plate on which $100 \mu \mathrm{L}$ of the diluted culture was plated. The media used for the dilution and the plating were M63 and LB, respectively. The plates were cultured overnight in an incubator (Yamato) at $37^{\circ} \mathrm{C}$, and then, a colony count was performed. At least four plates were used for each sampling point, and approximately 40 plates were used for a single growth curve based on the CFU. Three to five biological replications of the growth curves were performed for each strain or culture condition, which resulted in the consumption of approximately $2000 \mathrm{LB}$ agar plates in the present study.

\section{Measurement of the cellular ATP concentration}

Six different concentrations of the ATP solutions were prepared for the standard curve by diluting $10.4 \mathrm{mg} / \mathrm{mL}$ ATP (Roche) $10^{4} \sim 10^{9}$-fold with M63 medium. After placing $100 \mu \mathrm{L}$ of M63 medium or the six ATP solutions in 1.5-mL microtubes, $100 \mu \mathrm{L}$ of BacTiter-Glo ${ }^{\mathrm{Tm}}$ Microbial Cell Viability Assay solution (Promega) was added to each microtube according to the manufacturer's instructions. The fluorescence intensity was measured to prepare a calibration curve. A total of 10, 20, 50, and $100 \mu \mathrm{L}$ of each sampled culture was measured similarly to estimate the amount of ATP in the growing cells. Based on the calibration curve, the cellular ATP concentration was determined. A growth curve based on the ATP concentration was made to calculate the growth rate.

\section{Calculation of the growth rate}

Growth curves based on three different methods were created according to the temporal measurements of $\mathrm{OD}_{600}, \mathrm{CFU}$, and/or ATP as described above. A simple exponential regression toward the exponential growth phase in the growth curve was performed as follows.

$$
N_{i}=N_{0} e^{\mu t_{i}}
$$

where $N, t$ and $\mu$ represent the population density (cell concentration), time (h) and growth rate, respectively. Regression resulted in an exponent of the exponential slope as the growth rate $\left(\mathrm{h}^{-1}\right)$. The growth rates calculated from the growth curves of $\mathrm{OD}_{600}, \mathrm{CFU}$ and ATP were named $\mu_{\mathrm{OD}}, \mu_{\mathrm{CFU}}$ and $\mu_{\mathrm{ATB}}$ respectively.

\section{Detection of the cell size}

The cell culture (glycerol stock) was repeatedly diluted twofold with M63 medium, which led to a series of dilution rates from two to 1028 -fold. A total of $2 \mathrm{~mL}$ of the diluted cell mixtures was loaded on a 24-well microplate
(Iwaki). The microplate was incubated for $12 \mathrm{~h}$ in a microplate mixer (Taitec) with a rotation rate of $500 \mathrm{rpm}$ at $37{ }^{\circ} \mathrm{C}$ as described previously [38]. All of the wells (cell cultures) were subjected to measurements by both optical turbidity and a cell counter to reach a correlation between the $\mathrm{OD}_{600}$ and the mean cell size of the cell population. $\mathrm{OD}_{600}$ was measured using a $1 \mathrm{~mL}$ cuvette as described above. The cell size (volume) of the growing E. coli cells were measured using a cell counter (Beckman, Multisizer 4) as described previously [34]. Each culture (well) was measured individually. The median size of 3000 30,000 cells in the culture (well) was calculated and used as the representative cell size of the culture, which provided a precise correlation between cell size and $\mathrm{OD}_{600}$ of the same cell population (culture).

\section{Bacterial growth in a 96-well microplate}

Glycerol stocks of the E. coli cultures collected at the early exponential phase $\left(\mathrm{OD}_{600}<0.05\right)$ were diluted 100 to 1000-fold in M63 medium and well mixed using a vortex. The diluted cell mixture was loaded onto a 96-well microplate (Costar) in multiple wells at varied locations with $200 \mu \mathrm{L}$ of mixture per well as previously described [27]. The 96-well microplate was incubated in a plate reader (Epoch2, BioTek) with a rotation rate of $600 \mathrm{rpm}$ at $37{ }^{\circ} \mathrm{C}$. Bacterial growth was detected at an absorbance of $600 \mathrm{~nm}$ and read at intervals of $5 \mathrm{~min}$. The growth rates were calculated from every two reading points in a growth curve and according to the following equation.

$$
\mu=\ln \left(\frac{C_{j}}{C_{i}}\right) /\left(t_{j}-t_{i}\right)
$$

where $C_{i}$ and $C_{j}$ represent the two reads of $\mathrm{OD}_{600}$ values at two time points of $t_{j}$ and $t_{i}$, respectively, which were discontinuous at an interval of $1 \mathrm{~h}$ (i.e., every 20 intervals), although the reads were at intervals of $5 \mathrm{~min}$. Such discontinuously calculation largely masked the noisy records potentially occurred during the short interval measurements.

\section{Computational analysis of the bacterial growth}

The theoretical models for bacterial growth were evaluated using Python. The logistic and modified logistic models were fitted with 710 growth curves of $29 \mathrm{E}$. coli strains of various genome sizes growing in 96-well microplates. The raw data sets of these growth curves can be found at Springer Nature Research Data Support and can be accessed online via the following URL: https:// doi.org $/ 10.6084 / \mathrm{m} 9$.figshare.5918608. The details regarding the determination of the growth data set was previously described [27, 34], and the data sets of growth in M63 and LB media were used in the present study. 
Evaluation of the models (goodness of fit) was assessed based on the sum of squares, which were calculated according to the following equations.

$$
\begin{aligned}
& S S E=\sum\left(y_{i}-\hat{y}_{i}\right)^{2} \\
& R^{2}=1-\frac{S S E}{S S T}, \quad S S T=\sum\left(y_{i}-\bar{y}\right)^{2}
\end{aligned}
$$

where SSE, SST and $R^{2}$ represent the sum of squared errors, the sum of squares total, and the coefficient of determination, respectively. The script for the model regression can be freely requested at the following URL: http://www.trios.tsukuba.ac.jp/researcher/0000003489.

\section{Additional file}

Additional file 1: Supplemental Figures S1-S5. (PDF 1767 kb)

\section{Abbreviations}

ATP: Adenosine triphosphate; CFU: Colony forming unit; E. coli: Escherichia coli; LB: Luria-Bertani; $\mathrm{OD}_{600}$ : Optical density at a wavelength of $600 \mathrm{~nm}$; SSE: Sum of the squared errors

\section{Acknowledgments}

We thank the National BioResource Project and the National Institute of Genetics (Shizuoka, Japan) for providing the E. coli strains and the lab members for fruitful discussions.

\section{Funding}

This study was partially supported by the Tsukuba Basic Research Support Program (Type B). The funder had no role in the study design, data collection and interpretation or the decision to submit the work for publication.

\section{Availability of data and materials}

The raw data sets of the growth curves, which were used for the theoretical fitting, can be found at Springer Nature Research Data Support and can be accessed online via the following URL: https://doi.org/10.6084/m9.figshare.5918608.

\section{Authors' contributions}

KT, MK and KA performed the experiments; YYC, TY and BWY performed the analyses; BWY conceived the research and wrote the paper. All authors read and approved the final manuscript

\section{Ethics approval and consent to participate}

Not applicable.

\section{Consent for publication}

Not applicable.

\section{Competing interests}

The authors declare that they have no competing interests.

\section{Publisher's Note}

Springer Nature remains neutral with regard to jurisdictional claims in published maps and institutional affiliations.

\section{Author details}

${ }^{1}$ School of Life and Environmental Sciences, University of Tsukuba, 1-1-1 Tennodai, Ibaraki 305-8572, Japan. ${ }^{2}$ Institute of Biology and Information Science, East China Normal University, 3663 Zhongshan Road (N), Shanghai 200062, China.
Received: 22 May 2018 Accepted: 20 August 2018

Published online: 03 September 2018

\section{References}

1. Sezonov G, Joseleau-Petit D, D'Ari R. Escherichia coli physiology in LuriaBertani broth. J Bacteriol. 2007:189(23):8746-9.

2. Yates GT, Smotzer T. On the lag phase and initial decline of microbial growth curves. J Theor Biol. 2007;244(3):511-7.

3. Zaharia DC, Muntean AA, Popa MG, Steriade AT, Balint O, Micut R, Iftene C, Tofolean I, Popa VT, Baicus C, et al. Comparative analysis of Staphylococcus aureus and Escherichia coli microcalorimetric growth. BMC Microbiol. 2013;13:171.

4. Takeuchi R, Tamura T, Nakayashiki T, Tanaka Y, Muto A, Wanner BL, Mori H. Colony-live--a high-throughput method for measuring microbial colony growth kinetics--reveals diverse growth effects of gene knockouts in Escherichia coli. BMC Microbiol. 2014;14:171.

5. Peleg M, Corradini MG. Microbial growth curves: what the models tell us and what they cannot. Crit Rev Food Sci Nutr. 2011;51(10):917-45.

6. Blomberg A. Measuring growth rate in high-throughput growth phenotyping. Curr Opin Biotechnol. 2011;22(1):94-102.

7. Egli T. Microbial growth and physiology: a call for better craftsmanship. Front Microbiol. 2015;6:287

8. Fujikawa $\mathrm{H}$, Morozumi S. Modeling surface growth of Escherichia coli on agar plates. Appl Environ Microbiol. 2005;71(12):7920-6

9. Kargi F. Re-interpretation of the logistic equation for batch microbial growth in relation to Monod kinetics. Lett Appl Microbiol. 2009;48(4):398-401.

10. Desmond-Le Quemener E, Bouchez T. A thermodynamic theory of microbial growth. ISME J. 2014;8(8):1747-51.

11. Hermsen R, Okano H, You C, Werner N, Hwa T. A growth-rate composition formula for the growth of E. coli on co-utilized carbon substrates. Mol Syst Biol. 2015;11(4):801.

12. Alonso AA, Molina I, Theodoropoulos C. Modeling bacterial population growth from stochastic single-cell dynamics. Appl Environ Microbiol. 2014; 80(17):5241-53.

13. Koseki S, Nonaka J. Alternative approach to modeling bacterial lag time, using logistic regression as a function of time, temperature, $\mathrm{pH}$, and sodium chloride concentration. Appl Environ Microbiol. 2012;78(17):6103-12.

14. Winsor CP. The Gompertz curve as a growth curve. Proc Natl Acad Sci U S A. 1932;18(1):1-8.

15. Tonner PD, Darnell CL, Engelhardt BE, Schmid AK. Detecting differential growth of microbial populations with Gaussian process regression. Genome Res. 2017;27(2):320-33.

16. Swain PS, Stevenson K, Leary A, Montano-Gutierrez LF, Clark IB, Vogel J, Pilizota T. Inferring time derivatives including cell growth rates using Gaussian processes. Nat Commun. 2016:7:13766.

17. Liu B, Liu H, Pan Y, Xie J, Zhao Y. Comparison of the effects of environmental parameters on the growth variability of Vibrio parahaemolyticus coupled with strain sources and genotypes analyses. Front Microbiol. 2016:7:994

18. Roessler M, Sewald X, Muller V. Chloride dependence of growth in bacteria. FEMS Microbiol Lett. 2003;225(1):161-5.

19. Ponciano JM, Vandecasteele FP, Hess TF, Forney $L$, Crawford RL, Joyce P. Use of stochastic models to assess the effect of environmental factors on microbial growth. Appl Environ Microbiol. 2005;71(5):2355-64.

20. Harris CM, Kell DB. The estimation of microbial biomass. Biosensors. 1985; 1(1):17-84.

21. Madrid RE, Felice CJ. Microbial biomass estimation. Crit Rev Biotechnol. 2005:25(3):97-112

22. Myers JA, Curtis BS, Curtis WR. Improving accuracy of cell and chromophore concentration measurements using optical density. BMC Biophys. 2013:6(1):4.

23. Pla ML, Oltra S, Esteban MD, Andreu S, Palop A. Comparison of primary models to predict microbial growth by the plate count and absorbance methods. Biomed Res Int. 2015;2015:365025.

24. Lin HL, Lin CC, Lin YJ, Lin HC, Shih CM, Chen CR, Huang RN, Kuo TC. Revisiting with a relative-density calibration approach the determination of growth rates of microorganisms by use of optical density data from liquid cultures. Appl Environ Microbiol. 2010;76(5):1683-5.

25. Ziv N, Siegal ML, Gresham D. Genetic and nongenetic determinants of cell growth variation assessed by high-throughput microscopy. Mol Biol Evol. 2013;30(12):2568-78.

26. Hall BG, Acar H, Nandipati A, Barlow M. Growth rates made easy. Mol Biol Evol. 2014;31(1):232-8. 
27. Kurokawa M, Ying BW. Precise, high-throughput analysis of bacterial growth. J Vis Exp. 2017;127:56197.

28. Verissimo A, Paixao L, Neves AR, Vinga S. BGFit: management and automated fitting of biological growth curves. BMC Bioinformatics. 2013;14:283.

29. Sprouffske K, Wagner A. Growthcurver: an R package for obtaining interpretable metrics from microbial growth curves. BMC Bioinformatics. 2016;17:172.

30. Verhulst PF. Recherches mathématiques sur la loi d'accroissement de la population. Nouv mém de l'Academie Royale des Sci et Belles-Lettres de Bruxelles. 1845;18:1-41.

31. Verhulst PF. Deuxième mémoire sur la loi d'accroissement de la population. Mém de l'Academie Royale des Sci, des Lettres et des Beaux-Arts de Belgique. 1847;20:1-32.

32. Dalgaard P, Ross T, Kamperman L, Neumeyer K, McMeekin TA. Estimation of bacterial growth rates from turbidimetric and viable count data. Int J Food Microbiol. 1994;23(3-4):391-404.

33. Mizoguchi H, Sawano Y, Kato J, Mori H. Superpositioning of deletions promotes growth of Escherichia coli with a reduced genome. DNA Res. 2008;15(5):277-84.

34. Kurokawa M, Seno S, Matsuda H, Ying BW. Correlation between genome reduction and bacterial growth. DNA Res. 2016;23(6):517-25.

35. Vadia S, Levin PA. Growth rate and cell size: a re-examination of the growth law. Curr Opin Microbiol. 2015;24:96-103.

36. Yoshida M, Tsuru S, Hirata N, Seno S, Matsuda H, Ying BW, Yomo T. Directed evolution of cell size in Escherichia coli. BMC Evol Biol. 2014;14(1):257.

37. Ying BW, Honda T, Tsuru S, Seno S, Matsuda H, Kazuta Y, Yomo T. Evolutionary consequence of a trade-off between growth and maintenance along with ribosomal damages. PLoS One. 2015;10(8):e0135639.

38. Nishimura I, Kurokawa M, Liu L, Ying BW. Coordinated changes in mutation and growth rates induced by genome reduction. mBio. 2017;8(4):00676-17.

Ready to submit your research? Choose BMC and benefit from:

- fast, convenient online submission

- thorough peer review by experienced researchers in your field

- rapid publication on acceptance

- support for research data, including large and complex data types

- gold Open Access which fosters wider collaboration and increased citations

- maximum visibility for your research: over $100 \mathrm{M}$ website views per year

At BMC, research is always in progress.

Learn more biomedcentral.com/submissions 